\title{
Identification of post-translational modifications resulting from LH $\beta$ polymorphisms by matrix-assisted laser desorption time-of-flight mass spectrometric analysis of pituitary LH $\beta$ core fragment
}

\author{
E S Jacoby ${ }^{1}$, A T Kicman ${ }^{2}$ and R K Iles ${ }^{1,3}$ \\ ${ }^{1}$ The Williamson Laboratory, Department of Obstetrics and Gynaecology, St Bartholomew's and the Royal London School of Medicine and Dentistry, \\ West Smithfield, London EC1A 7BE, UK \\ ${ }^{2}$ Drug Control Centre, Franklin-Wilkins Building, Stamford Street, London SE1 9NN, UK \\ ${ }^{3}$ School of Biological and Applied Science, The University of North London, Holloway Road, London N7 8DB, UK \\ (Requests for offprints should be addressed to R K lles, The Williamson Laboratory, St Bartholomew's Hospital, West Smithfield, London EC1A 7BE, \\ UK; Email: r.k.iles@qmul.ac.uk)
}

\begin{abstract}
Metabolism of the human chorionic gonadotrophin (hCG)- and LH $\beta$-subunits (hCG $\beta$, LH $\beta$ ) terminates with the urinary excretion of core fragment (hCG $\beta \mathrm{cf}$, LH $\beta \mathrm{cf}$ ) molecules that retain antigenic shape and constituent $N$-linked carbohydrate moieties. We have previously demonstrated the resolved mass spectra of hCGßcf, from which the carbohydrate moieties present at two $\mathrm{N}$-linked glycosylation sites were identified. $\mathrm{LH} \beta c f$ was subjected to the same mass spectrometric analysis. As $\mathrm{LH} \beta$ shares $82 \%$ homology with hCG $\beta$ but possesses only one glycosylation consensus site a simpler spectral fingerprint of LH $\beta c f$ glycoforms was expected. LH $\beta$ cf was reduced with dithiothreitol and analysed by matrix-assisted laser desorption/ionisation time-of-flight mass spectrometry. Glycoforms were predicted by subtracting the peptide mass from the $\mathrm{m} / \mathrm{z}$ values of the observed peaks and then sequentially subtracting the masses of the monosaccharide residues of hCG $\beta N$-linked carbohydrates reported in the literature. The mass spectra of LH $\beta c f$ revealed a broad single peak ranging from $\mathrm{m} / \mathrm{z} 8700$ to 10700 . Following reduction, this peak was replaced by a set of partially resolved peaks between $\mathrm{m} / \mathrm{z} 4130$ and 5205 corresponding to glycosylated forms of the peptide LH $36-40$. A peak at $\mathrm{m} / \mathrm{z} 4252.2$ corresponded to the non-glycosylated peptide LHß55-93. Remaining peaks indicated that the pooled sample comprised a wide set of glycoforms, contained $\mathrm{LH} \beta \mathrm{cf}$ with two $\mathrm{N}$-linked carbohydrate moieties and indicated evidence of further glycosylation due to amino acid substitution in polymorphic variants. This is evidence that a single nucleotide polymorphism alters the post-translational modification of a protein and hence its structural phenotype.
\end{abstract}

Journal of Molecular Endocrinology (2003) 30, 239-252

\section{Introduction}

Luteinizing hormone $(\mathrm{LH})$ is a dimeric glycoprotein that is synthesised and secreted by the anterior pituitary gland. LH is an essential requirement in the stimulation of follicular growth, oocyte maturation, ovulation and in promoting spermatogenesis. Its mode of action is via stimulation of steroidogenesis in both testicular and ovarian gonadal tissues. The structure of LH is analogous to other members of the glycoprotein hormone family that includes chorionic gonadotrophin, thyroid-stimulating hormone and follicle-stimulating hormone. Each consists of an $\alpha$-subunit that is common to all members and a unique $\beta$-subunit that confers specific hormonal activity (Pierce \& Parsons 1981). Although there are no defining crystallography data describing the $\mathrm{LH} \beta$-subunit $(\mathrm{LH} \beta)$ it is assumed that its molecular structure is essentially similar to that of the human chorionic gonadotrophin $\beta$-subunit (hCG $\beta$ ), with which it shares a high degree of linear sequence homology and a 

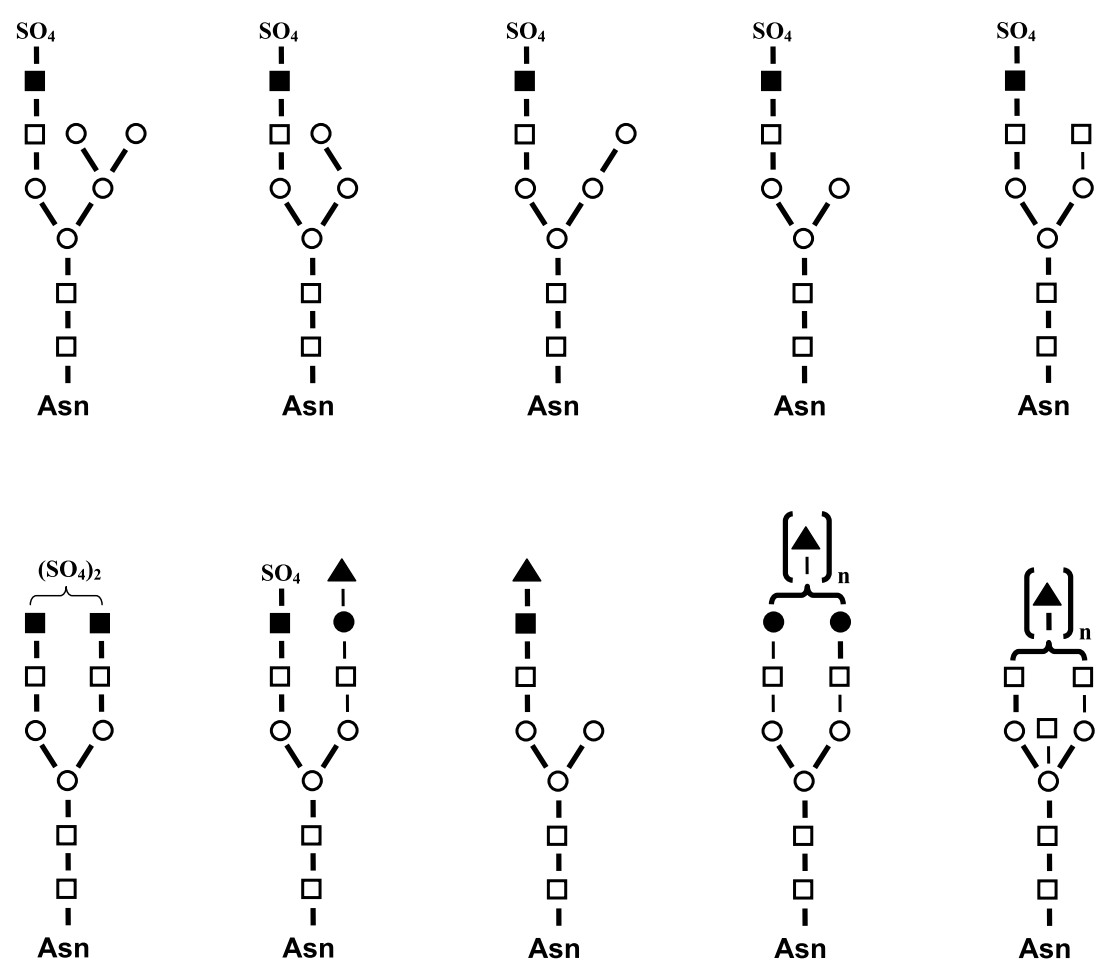

Figure $1 \mathrm{~N}$-linked carbohydrates attributed to intact LH by Green \& Baenziger $(1988 a, b)$ and subsequently found to be present on LH $\beta$ by Weisshaar et al. (1991). N-acetylglucosamine ( $\square$ ); mannose (O);

$\mathrm{N}$-acetylgalactosamine $(\boldsymbol{\square})$; galactose $(\bullet)$; sialic acid $(\mathbf{\Lambda}) ; n=1$ or 2 .

target receptor (Carlsen et al. 1973, Shome \& Parlow 1973, Lapthorn et al. 1994, Wu et al. 1994). As with other glycoprotein hormones, LH is characterised by carbohydrate moieties present on both subunits that act to determine receptor affinity and metabolic clearance (Ryan et al. 1987). The $\mathcal{N}$-linked carbohydrates (shown in Fig. 1) found on both the LH $\alpha$-subunit (Asn 52 and Asn 78) and the $\beta$-subunit (Asn 30) confer a high degree of microheterogeneity being composed of a wide population of complex and hybrid sugars (Green \& Baenziger 1988a,b, Weisshaar et al. 1991). (All $\mathcal{N}$-linked glycans possess the pentasaccharide Man $\alpha$ 1-6(Man $\alpha$ 1-3)Man $\beta 1-4$ GlcNAc $\beta 1-4$ GlcNAc (Kornfeld \& Kornfeld 1985) commonly termed the trimannosyl core. Based on the residues added to the trimannosyl core, $\mathcal{N}$-linked glycans are further classified into three subgroups: complex, when no mannosyl residues are present in subsequent branching; high mannose, when mannosyl residues only are attached to the core; and hybrid, which contain both complex and high mannose branches.) $\mathcal{N}$-linked glycans in LH possess terminal sulphate residues in the case of the hybrid carbohydrates and either terminal sulphate or sialic residues acid or a combination in the case of the complex sugars (Green \& Baenziger $1988 a, b)$.

The terminal core fragment of the LH $\beta$-subunit $(\mathrm{LH} \beta \mathrm{cf})$ was first isolated as an $\mathrm{LH}$ degradation product in human pituitary glycoprotein extracts (Birken et al. 1993). Indeed LH, its free subunits and LH $\beta$ cf are all found in the pituitary (Birken et al. 1996), indicating that some proteolytic degradation of the free LH $\beta$-subunit takes place there. Due to the high structural homology with hGG $\beta$ it is likely that circulating LH $\beta$ (O’Connor et al. 1998) shares a similar metabolic fate being largely degraded to the terminal core fragment in the kidneys (Markkanen et al. 1979). Evidence supporting the existence of urinary LH $\beta c f$ is based on the detection of immunoreactive material resembling human chorionic gonadotrophin $\beta$ subunit (hCG $\beta \mathrm{cf}$ ) in mid-menstrual and postmenopausal urine (Iles et al. 1992, 1999, Neven et al. 1993). 

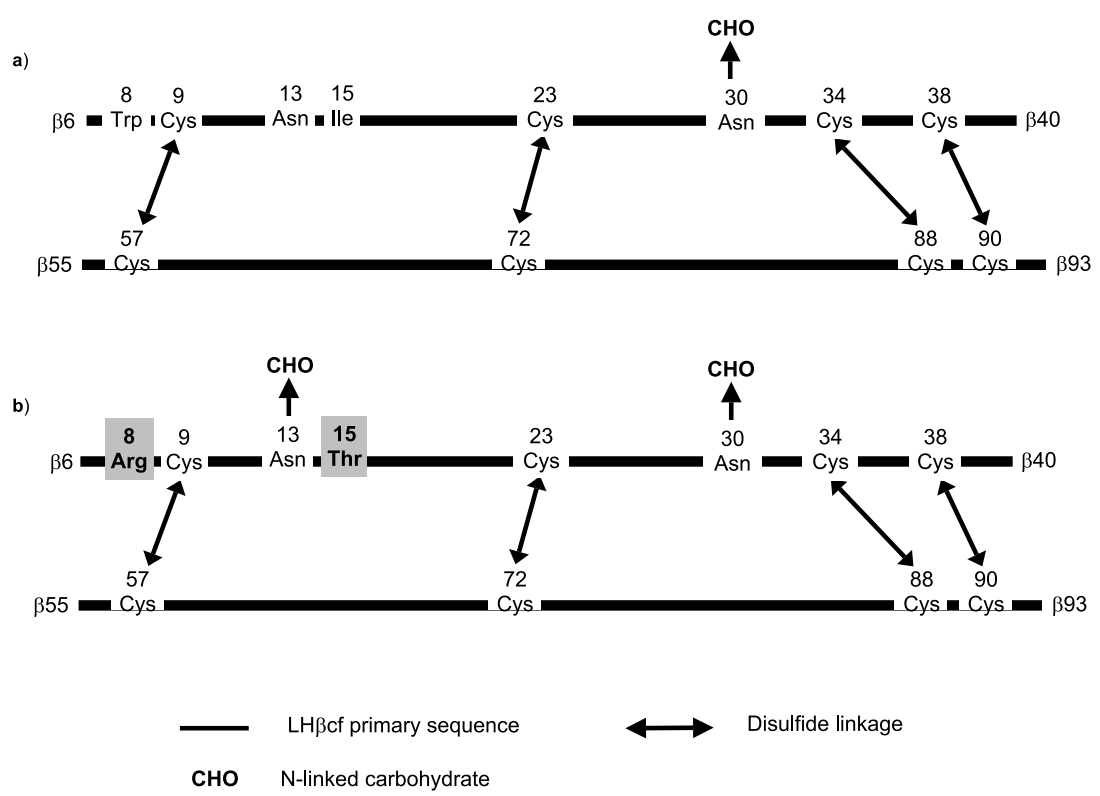

Figure 2 Schematic diagram of the primary sequence of LH $\beta c f$ peptides showing disulfide bonds and $\mathrm{N}$-linked glycosylation positions in the wild-type metabolite (a) and in that of the common polymorphic variant (b) where the amino acid substitutions are also indicated.

The terminal urinary metabolite of hCG $\beta c f$ is composed of two peptides: $\beta 6-40$ which possesses two $\mathcal{N}$-glycosylation consensus sequences and $355-92$ which is not glycosylated (Birken et al. 1988). The dipeptide is stabilised by a tight grouping of four cystine residues and has a mass of approximately $10 \mathrm{kDa}$ (Fig. 2a). Structural analysis suggests that $\mathrm{LH} \beta \mathrm{cf}$ is more heterogeneous in the length of its constituent peptides than hCG $\beta$ cf. Matrix-assisted laser desorption/ ionisation (MALDI) time-of-flight (TOF) mass spectrometry (MS) of reduced, carboxymethylated and deglycosylated LHßcf has revealed the presence of two non-glycosylated peptides spanning not only amino acids $\beta 55-93$ but also $\beta 49-93$ (Birken et al. 2001). The primary structure of the glycosylated peptide, not subjected to MS, has previously been determined to be $\beta 6-40$ (Birken et al. 1993, O’Connor et al. 1998).

Up to ten mutations and polymorphisms in the LH $\beta$ gene have been described including six silent polymorphisms in both exons and introns (reviewed in Huhtaniemi et al. 1999). Following the failure to detect serum LH in some patients by two-site immunoassays that utilised highly specific monoclonal antibody pairs (Pettersson et al. 1991), mutations altering the antigenic structure of the
LH $\beta$-subunit were identified. Of particular interest is a genetic variant of $\mathrm{LH}(\mathrm{vLH})$ that arises from two single point mutations in the LH $\beta$ gene that each alters the primary amino acid sequence: Trp8 $\rightarrow$ Arg $\quad($ TGG $\rightarrow$ CGG $)$ and Ile15 $\rightarrow$ Thr $(\mathrm{ATC} \rightarrow \mathrm{ACG}$ ) (Furui et al. 1994, Pettersson et al. 1994, Nilsson et al. 1998). An extra glycosylation consensus sequence (Asn-X-Thr/Ser) is thereby introduced into the $\mathrm{LH} \beta$-subunit by the second mutation which, it may be speculated, might permit the attachment of an $\mathcal{N}$-linked oligosaccharide moiety at Asn 13 .

Recently, we utilised MALDI-TOF MS to elucidate the carbohydrates residual on hCG $\beta c f$ (Jacoby et al. 2000) following reports of an increase in human chorionic gonadotrophin (hCG) hyperglycosylation in the urine of individuals with Downs' pregnancies or with gynaecological cancers (Elliott et al. 1997, Cole et al. 1998, 1999). Direct analysis of hCG $\beta c f$ was not possible as the technique did not prove discriminating enough to identify individual glycoforms because of the lack of resolution between them. To circumvent this problem the four cystine residues between the two polypeptides were reduced with dithiothreitol (DTT) prior to MS analysis (Kussmann et al. 1997). This separated the non-glycosylated $\beta 55-92$ chain 
from the glycosylated $\beta 6-40$ chains while increasing the resolution between all peaks and producing a distinctive 'fingerprint' spectrum (Jacoby et al. 2000). It was then possible to determine the mass of each glycosylation variant on the $\beta 6-40$ chain by calculating the difference in mass between each observed peak to the mass of its corresponding non-glycosylated primary amino acid sequence. This study set out to investigate the glycosylation profile of a pool of $\mathrm{LH} \beta \mathrm{cf}$ following treatment with DTT. The expectation was that as the wild-type LH $\beta$ cf retains a single $\mathcal{N}$-linked carbohydrate moiety at Asn 30 then a simpler fingerprint spectrum would be obtained by contrast with that acquired from hCG $\beta$ cf.

\section{Materials and methods}

\section{Materials}

The LH $\beta c$ from pooled pituitary tissue used in this study, batch no. 697, was previously isolated by Birken et al. (1993) and was a kind gift from Dr Steven Birken, Columbia University, New York, NY, USA. This, rather than that isolated from urine, was utilised as sufficient was readily available in the pure form. DTT, for the reduction of disulfide bonds, and $\mathrm{NH}_{4} \mathrm{HCO}_{3}$ were obtained from Sigma-Aldrich Co. Ltd, UK. The MALDI MS matrix 3,5-dimethoxy-4-hydroxycinnamic acid (sinapinic acid: SA) was similarly purchased from Sigma-Aldrich Co. Ltd and used without further purification. Acetonitrile and trifluoroacetic acid (TFA) were of analytical grade and obtained from VWR International Ltd., UK.

\section{MALDI-TOF MS}

To acquire spectra of LH $\beta$ cf, 10 pmol $(0.5 \mu \mathrm{l}$ of $20 \mu \mathrm{mol} / \mathrm{l}$ in distilled and deionised $\left.\mathrm{H}_{2} \mathrm{O}\left(\mathrm{dH}_{2} \mathrm{O}\right)\right)$ was applied to a stainless steel MALDI MS target and mixed together with $1 \cdot 0 \mu \mathrm{l} \mathrm{SA}(20 \mathrm{~g} / \mathrm{l}$ in $70: 30$ $(\mathrm{v} / \mathrm{v})$ acetonitrile $-1 \mathrm{ml} / \mathrm{l}$ TFA in $\mathrm{dH}_{2} \mathrm{O}$ ) and air dried. The method by which spectra of reduced glycoforms were obtained has been previously reported (Jacoby et al. 2000). Briefly 10 pmol LH $\beta$ cf $\left(0.5 \mu \mathrm{l}\right.$ of $20 \mu \mathrm{mol} / \mathrm{l}$ in $\left.\mathrm{dH}_{2} \mathrm{O}\right)$ and $0.5 \mu \mathrm{l}$ DTT $\left(100 \mathrm{mM} / \mathrm{l}\right.$ in $\left.100 \mathrm{mM} / 1 \mathrm{NH}_{4} \mathrm{HCO}_{3}, \mathrm{pH} 8.8\right)$ were mixed together on a MALDI MS target and incubated at room temperature. When this mixture was virtually dry $0.5 \mu \mathrm{l} 1 \mathrm{ml} / \mathrm{l}$ TFA in $\mathrm{dH}_{2} \mathrm{O}$ was added to the remaining droplet. The mixture was again allowed to partially dry before adding $1 \cdot 0 \mu \mathrm{l}$ SA $(20 \mathrm{~g} / 1$ in acetonitrile- $0 \cdot 1 \%$ TFA, $70: 30 \mathrm{v} / \mathrm{v})$ and air dried as before. The instrument was calibrated externally using horse heart cytochrome C $\left(M_{\mathrm{r}} 12\right.$ 360.1; Sigma-Aldrich Co. Ltd). Mass spectrometric analysis was carried out on a VG TOF Spec E (Micromass Ltd, UK) with a $1.5 \mathrm{~m}$ flight tube operating at an accelerating voltage of $20 \mathrm{kV}$ in positive linear mode. A pulsed nitrogen laser $\left(\lambda_{\max }=337 \mathrm{~nm}\right)$ was utilised to desorb ions from the samples which were detected by a microchannel plate detector at a sampling rate of $500 \mathrm{MHz}$. Spectra were generated by summing 30-40 laser shots. Data were acquired from the instrument operating in the positive linear mode.

\section{Treatment of results}

Initially the peak relating to the non-glycosylated LH $\beta$ cf peptide ( $\beta 55-93$ ) was internally calibrated to the average molecular mass of its given primary sequence: $[\mathrm{M}+\mathrm{H}]^{+} 4256 \cdot 0$ (calculated using the computer software MassLynx 3·2; Micromass Ltd). This facilitated the automatic correction of the mass values of the remaining peaks to their correct values.

In order to determine the inferred mass values of the LH $\beta c f$ carbohydrate moieties, the average molecular mass $\left([\mathrm{M}+\mathrm{H}]^{+} 3768.4 \mathrm{Da}\right)$ of the primary sequence of the glycosylated LH $\beta c f$ polypeptide ( $\beta 6-40)$ was subtracted from the mass $\left([\mathrm{M}+\mathrm{H}]^{+}\right)$values of the acquired peaks (Table 1). The carbohydrate content of these peaks was then deduced by the sequential subtraction of the masses of the sugar residues present in LH $\beta$-subunit carbohydrates (Table 2). Carbohydrate structures (Table 3) were then predicted from the deduced monosaccharide content, taking into account the small difference between the calculated and the observed masses $(\leq 0 \cdot 40 \%)$. When subtraction of the average molecular mass of the wild-type glycosylated LH $\beta$ cf polypeptide did not produce a value from which a carbohydrate could be determined then the same procedure was used, subtracting the average molecular mass of the variant glycosylated LH $\beta$ cf polypeptide containing either Trp 8 $\rightarrow$ Arg $\left([\mathrm{M}+\mathrm{H}]^{+} 3744 \cdot 4 \mathrm{Da}\right)$ and Ile15 $\rightarrow$ Thr $\left([\mathrm{M}+\mathrm{H}]^{+}\right.$ $3762 \cdot 4 \mathrm{Da})$ mutations or both mutations $\left([\mathrm{M}+\mathrm{H}]^{+}\right.$ $3732 \cdot 4 \mathrm{Da})$. Conformational information describing the anomeric glycosidic linkages within the LH $\beta$ 
Table 1 Peptides of LH $\beta$ cf released after DTT reduction, detected by MALDI-TOF MS

\begin{tabular}{|c|c|c|c|c|c|c|c|}
\hline & $\begin{array}{l}\text { Observed } \\
\text { mass } \\
\left([\mathrm{M}+\mathrm{H}]^{+}\right)\end{array}$ & $\begin{array}{l}\text { Predicted } \\
\text { LH } \beta \\
\text { variant }\end{array}$ & $\begin{array}{l}\text { Mass of } \\
\text { inferred } 1^{\circ} \\
\text { sequence } \\
\left([\mathrm{M}+\mathrm{H}]^{+}\right)^{\mathrm{a}}\end{array}$ & $\begin{array}{l}\text { Mass }-1^{\circ} \\
\text { sequence }\end{array}$ & $\begin{array}{l}\text { Predicted mass } \\
\text { of residual } \\
\mathrm{CHO}\end{array}$ & $\Delta^{\mathrm{b}}$ & $\Delta \%$ \\
\hline \multicolumn{8}{|l|}{ Peak } \\
\hline 1 & $4151 \cdot 6$ & mut8 & $3744 \cdot 4$ & $407 \cdot 2$ & $406 \cdot 4$ & $0 \cdot 8$ & 0.02 \\
\hline 2 & 4321.9 & wt & $3744 \cdot 4$ & 547.5 & 552.5 & $-5 \cdot 0$ & -0.12 \\
\hline 3 & $4360 \cdot 1$ & mut15 & $3762 \cdot 4$ & 597.7 & 609.6 & -11.9 & 0.27 \\
\hline 4 & $4395 \cdot 1$ & - & - & - & - & - & - \\
\hline 5 & $4424 \cdot 7$ & $\mathrm{dbl}$ mut & 3732.4 & 692.4 & $698 \cdot 7$ & $-6 \cdot 3$ & -0.14 \\
\hline 6 & $4466 \cdot 7$ & $\mathrm{dbl}$ mut & $3732 \cdot 4$ & 734.4 & $730 \cdot 7$ & $3 \cdot 7$ & 0.08 \\
\hline 7 & $4505 \cdot 7$ & wt & $3774 \cdot 4$ & 731.3 & $730 \cdot 7$ & 0.6 & 0.01 \\
\hline 8 & $4537 \cdot 1$ & mut15 & $3762 \cdot 4$ & 774.7 & 771.7 & $3 \cdot 0$ & 0.07 \\
\hline 9 & $4590 \cdot 6$ & mut15 & $3762 \cdot 4$ & $828 \cdot 3$ & $812 \cdot 8$ & $15 \cdot 5$ & 0.34 \\
\hline 10 & 4648.5 & wt & $3774 \cdot 4$ & 874.1 & $876 \cdot 8$ & $-2 \cdot 8$ & -0.06 \\
\hline 11 & $4681 \cdot 0$ & $\mathrm{dbl}$ mut & $3732 \cdot 4$ & 948.6 & 958.9 & $-10 \cdot 3$ & -0.22 \\
\hline 12 & $4718 \cdot 6$ & mut15 & $3762 \cdot 4$ & $956 \cdot 2$ & 958.9 & $-2 \cdot 7$ & -0.06 \\
\hline 13 & 4760.5 & $\mathrm{dbl}$ mut & $3732 \cdot 4$ & $1028 \cdot 1$ & 1038.9 & $-10 \cdot 8$ & -0.23 \\
\hline 14 & $4808 \cdot 3$ & $\mathrm{dbl}$ mut & $3732 \cdot 4$ & $1075 \cdot 9$ & $1080 \cdot 0$ & $-4 \cdot 1$ & -0.09 \\
\hline 15 & 4893.9 & mut15 & $3762 \cdot 4$ & 1131.5 & $1137 \cdot 0$ & -5.5 & -0.11 \\
\hline 16 & $5006 \cdot 9$ & mut15 & $3762 \cdot 4$ & 1244.5 & $1242 \cdot 1$ & $2 \cdot 4$ & 0.05 \\
\hline 17 & 5101.5 & mut15 & $3762 \cdot 4$ & $1339 \cdot 1$ & $1340 \cdot 2$ & $-1 \cdot 1$ & -0.02 \\
\hline 18 & $5146 \cdot 2$ & mut15 & $3762 \cdot 4$ & $1383 \cdot 8$ & $1388 \cdot 3$ & $-4 \cdot 5$ & -0.09 \\
\hline 19 & $5204 \cdot 6$ & mut8 & $3744 \cdot 4$ & $1460 \cdot 2$ & 1461.3 & $-1 \cdot 1$ & -0.02 \\
\hline
\end{tabular}

a Mass of the primary sequences of the glycosylated LH $\beta c f$ peptide: $\beta 6-40$.

${ }^{b}$ Difference between the calculated mass of the expected total carbohydrate $(\mathrm{CHO})$ and the inferred mass following subtraction of the mass of the primary sequence from the peak mass.

mut, mutation; wt, wild-type; dbl, double mutant.

$\mathcal{N}$-linked carbohydrate structures have been reported previously (Green \& Baenziger 1988a,b, Weisshaar et al. 1991) and were taken into account in our analysis.

\section{Results}

A typical spectrum of LH $\beta c f$ obtained by MALDI-TOF MS using the matrix SA is shown in Fig. 3. The spectrum is characterised by a single

Table 2 Relative molecular mass (RMM) of the monosaccharides and terminal groups expected to be present in the LH $\beta$-subunit $N$-linked carbohydrates

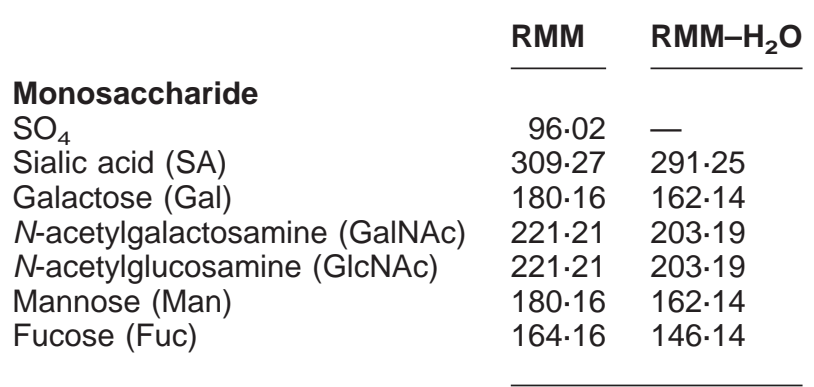

www.endocrinology.org broad peak at $m / z$ 8700-10 700. The discernible peaks present at $m / z \quad 9320$ and 9475 are presumably partially resolved glycoforms but were not always as well defined on all the spectra acquired of the intact core fragment. Following reduction with DTT the broad peak was replaced by a set of partially resolved peaks between $\mathrm{m} / \mathrm{z}$ 4130 and 5205 (Fig. 4). Resolution was improved by allowing the data analysis software to determine the $\mathrm{m} / \mathrm{z}$ values of the centroid positions of the spectral peaks (Fig. 5) and these masses were used to predict the carbohydrates present. The peak at $m / z 4252 \cdot 3$ was deemed to arise from the non-glycosylated peptide chain $(\beta 55-93)$ because the $m / z$ value lies within the $0.5 \%$ error margin allowed for the linear operating mode of the MALDI-TOF instrument. The low percentage errors between the expected and the observed mass values of the acquired peaks indicated the likelihood that real glycoforms were detected despite the fact that $\mathrm{LH} \beta \mathrm{cf}$ asparagine-linked glycoforms were not observed directly (Table 1). 
Table 3 Proposed structures of the oligosaccharides in the glycoforms contributing to the microheterogeneity of wild-type LH $\beta$ cf (peaks 2, 7 and 10) and LH $\beta c f$ containing a Trp $8 \rightarrow \operatorname{Arg}$ substitution (peaks 1 and 19). The composition of these structures (as well as those in Tables 4 and 5) are presumed from the masses acquired for the glycopeptides while the indicated linkages have been adopted from previous extensive characterisation of those oligosaccharides (Green \& Baenziger 1988a,b, Weisshaar et al. 1991)

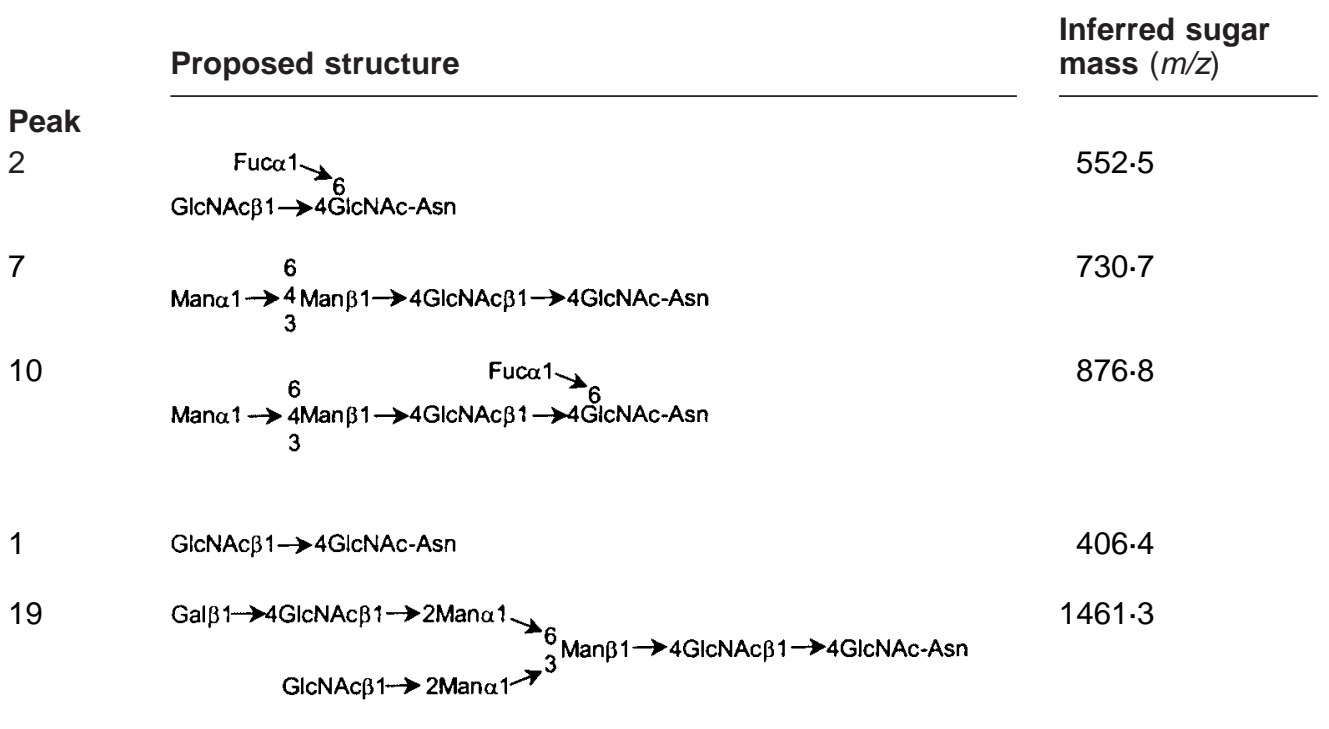

$\mathcal{N}$-linked carbohydrate moieties, shown in Tables 3-5, were determined as described above. Where the number of monosaccharide residues calculated for the carbohydrate moieties associated with the mass spectral peaks precluded the determination of a single glycoform or a single pair of glycoforms then possible alternative structures are suggested. Initially the mass of the sugars was calculated assuming that the glycosidic linkage was to a peptide arising from a wild-type peptide $\left(\mathrm{LH} \beta c \mathrm{cf}_{\mathrm{wt}}\right)$ with no polymorphic variation (Table 3 ). This enabled identification of the glycosylation of the glycoforms at peaks 2, 7 and 10. Peak $2(\mathrm{~m} / \mathrm{z}$ 4321.9) arises from a polypeptide possessing a single truncated and fucosylated monoantennary oligosaccharide $\left(\mathrm{GlcNAc}_{2} \mathrm{Fuc}\right)$ with a predicted mass of $552 \cdot 5$, whereas the polypeptide giving rise to peak $7(\mathrm{~m} / \mathrm{z} 4505 \cdot 7)$ has a single truncated non-fucosylated monoantennary oligosaccharide $\left(\mathrm{GlcNAc}_{2} \mathrm{Man}_{2}\right)$ with a predicted mass of $730 \cdot 7$. Similarly peak $10(\mathrm{~m} / \mathrm{z}$ 4648.5) arises from a polypeptide possessing a single truncated monoantennary oligosaccharide that is additionally fucosylated $\left(\mathrm{GlcNAc}_{2} \mathrm{Man}_{2} \mathrm{Fuc}\right)$ with a predicted mass of $876 \cdot 8$. Carbohydrates associated with the remaining peaks could not be determined for a wild-type LH $\beta$ cf. However, subtracting the average molecular mass for the glycosylated peptide with a Trp $8 \rightarrow$ Arg mutation permitted the determination of the glycosylation for peaks 1 and 19 (Table 3). The predicted mass of 406.4 for the carbohydrate moiety of the glycoform at peak $1(\mathrm{~m} / \mathrm{z} 4151.6)$ indicates a disaccharide $\left(\mathrm{GlcNAc}_{2}\right)$. The predicted mass of the carbohydrate moiety attached to peak $19(\mathrm{~m} / \mathrm{z} 5204 \cdot 6)$ suggests a biantennary oligosaccharide. This peak arises from a polypeptide possessing a non-fucosylated trimannosyl core attached to two additional $\mathcal{N}$-acetylglucosamine residues as well as a galactose residue $\left(\mathrm{GalMan}_{3} \mathrm{GlcNAc}_{4}\right)$ with a predicted carbohydrate mass of $1461 \cdot 3$. Subtracting the average molecular mass for the glycosylated peptide with an Ile $15 \rightarrow$ Thr substitution then permitted the determination of the glycosylation for peaks $3,8,9,12$, 15, 16, 17 and 18 (Table 4). Peak $3(\mathrm{~m} / z$ 4360. 1 ) appears to arise from a polypeptide with two monoantennary carbohydrate moieties (GlcNAc and $[\mathrm{GlcNAc}]_{2}$ ) with a predicted mass of $609 \cdot 6$. The predicted mass of the carbohydrate moiety attached to peak $8(\mathrm{~m} / z 4537 \cdot 1), 771 \cdot 7$, suggests a polypeptide possessing a single truncated monoantennary carbohydrate (ManGlcNAc 3 ) or two 


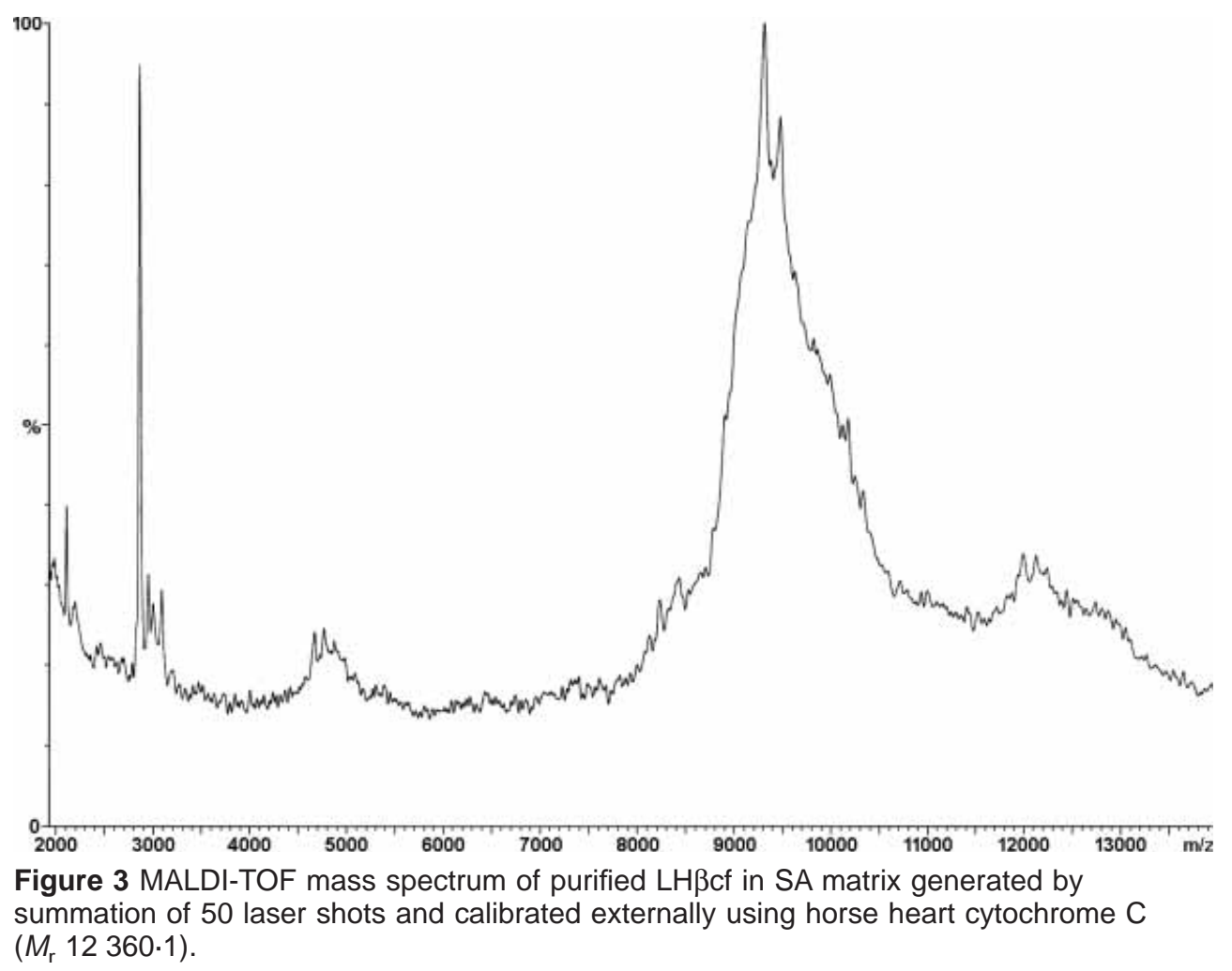

monoantennary carbohydrate moieties (GlcNAc and ManGlcNAc $\left.{ }_{2}\right)$. Peak $9(\mathrm{~m} / z$ 4590.6) and peak $12(\mathrm{~m} / \mathrm{z} 4718 \cdot 6)$ arise from a polypeptide possessing two single and truncated monoantennary disaccharides $\left(\left[\mathrm{GlcNAc}_{2}\right]_{2}\right)$ of which one, in peak 12 , is fucosylated. The predicted carbohydrate mass of the glycoforms seen at peaks 9 and 12 is $812 \cdot 8$ and 958.9 respectively. The masses derived for the glycosylation moieties attached to the polypeptides giving rise to peaks 15, 16 and 17 allow the possibility for several carbohydrate permutations on each protein. The glycoform at peak $15(\mathrm{~m} / \mathrm{z} 4893.9)$ has a predicted carbohydrate mass of $1137 \cdot 0$ indicating either a single non-fucosylated monoantennary oligosaccharide $\left(\right.$ GalNAcMan $\left._{2} \mathrm{GlcNAc}_{3}\right)$ or alternatively pairs of monoantennary carbohydrates ([ManGlcNAc $]_{2}$ or $\left[\mathrm{Man}_{2} \mathrm{GlcNAc}_{2}\right.$ and $\left.\mathrm{GlcNAc}_{2}\right]$ or $\left[\mathrm{Man}_{2} \mathrm{GlcNAc}_{3}\right.$ and GlcNAc]). Peak $16(\mathrm{~m} / z$ 5006.9) arises from a glycoform consisting of a fucosylated trimannosyl core possessing an additional $\mathcal{N}$-acetylglucosamine residue as a bi- or tri-antennary extension or linked to a second asparagine residue. Alternatively, the carbohydrate, with a predicted mass of $1242 \cdot 1$, may be present as a single fucosylated monoanten- nary structure. Peak $17(\mathrm{~m} / z$ 5101.5) arises from a polypeptide possessing two truncated nonfucosylated monoantennary sugars, with a total predicted carbohydrate mass of $1340 \cdot 2$, with several possible structural permutations. The glycosylation moiety of the polypeptide giving rise to peak $18(\mathrm{~m} / z 5146 \cdot 2)$ can only occur as a fucosylated monoantennary and a fucosylated trimannosyl core (GlcNAcFuc and $\mathrm{Man}_{3} \mathrm{GlcNAc}_{2} \mathrm{Fuc}$ ) with a total predicted mass of 1388.3. The carbohydrate moieties of the glycoforms that give rise to remaining peaks 5, 6, 11, 13 and 14 were determined assuming that both mutations, Trp $8 \rightarrow \operatorname{Arg}$ and Ile $15 \rightarrow$ Thr, were present in the reduced LH $\beta$ cf molecule (Table 5). In peak $5(\mathrm{~m} / z 4424 \cdot 7)$ the carbohydrate moiety appears to consist of two fucosylated $\mathcal{N}$ acetylglucosamine residues $\left([\mathrm{GlcNAcFuc}]_{2}\right)$ with a predicted mass of $698 \cdot 7$, whereas the glycoform giving rise to peak $6(\mathrm{~m} / z 4466 \cdot 7)$ contains a single monoantennary sugar $\left(\mathrm{GlcNAc}_{2} \mathrm{Man}_{2}\right)$ with a predicted mass of $730 \cdot 7$. Peak $11(\mathrm{~m} / \mathrm{z} 4681 \cdot 0)$ arises from a glycoform that contains a pair of di-saccharides of which one is fucosylated $\left(\mathrm{GlcNAc}_{2}\right.$ and $\left.\mathrm{GlcNAc}_{2} \mathrm{Fuc}\right)$ with a predicted mass 


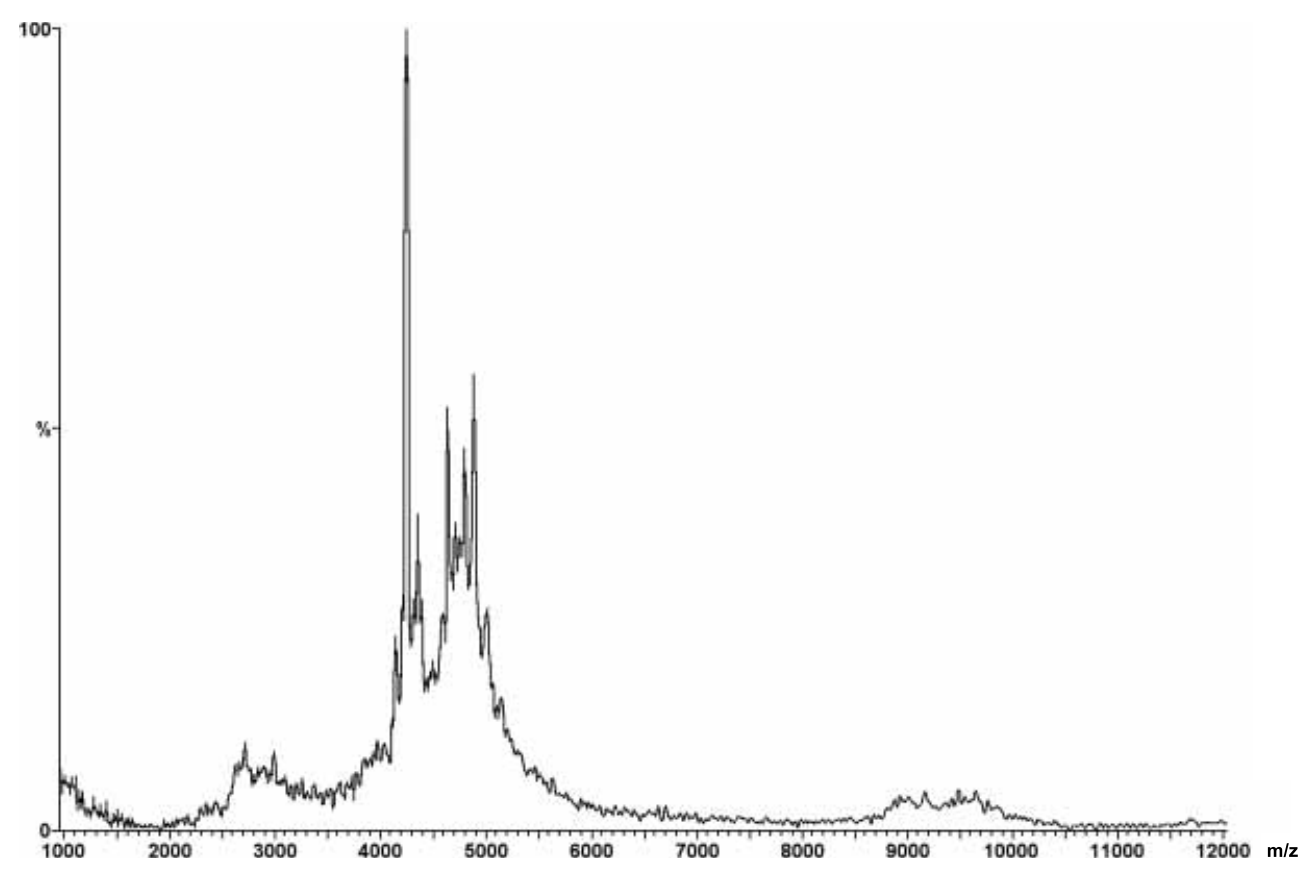

Figure 4 MALDI-TOF mass spectrum of LH $\beta c f$ after 'on-target' reduction and using SA matrix. The spectrum was generated by summation of 50 laser shots and calibrated internally using fragment mass $4256 \cdot 0$.

of 958.9. The glycoform at peak $13(\mathrm{~m} / z$ 4760.5) indicates a polypeptide with a predicted carbohydrate mass of 1038.9 suggesting a single fucosylated trimannosyl core $\left(\mathrm{Man}_{3} \mathrm{GlcNAc}_{2} \mathrm{Fuc}\right)$. Finally, the polypeptide giving rise to peak $14(\mathrm{~m} / \mathrm{z}$ $4808 \cdot 3)$ possesses a glycosylation moiety, with a predicted mass of $1080 \cdot 0$, which occurs either as two monoantennary carbohydrates $\left(\mathrm{Man}_{2} \mathrm{GlcNAc}_{2}\right.$ and GlcNAc) of which one is fucosylated or a single fucosylated monoantennary structure $\left(\mathrm{Man}_{2} \mathrm{GlcNAc}_{3} \mathrm{Fuc}\right)$. There were a number of peaks remaining in the mass spectrum of DTT-reduced LH $\beta c f$ for which carbohydrates were not able to be determined. These include a number of low intensity peaks for which mass values could not be acquired by the software as well as a peak of moderate intensity (peak 4) whose mass $(\mathrm{m} / z 4395 \cdot 1)$ could not be correlated with the mass of the $\mathrm{LH} \beta_{\mathrm{wt}}$ or vLH $\beta$ peptide primary sequences.

\section{Discussion}

Mass spectral and ion chromatography analyses of the structure of pituitary LH $\beta$ cf have predicted that, although the LH $\beta$-subunit is acted on by proteases in the pituitary, a lack of glycosidases there might leave its carbohydrate moieties intact (Birken et al. 1996, O'Connor et al. 1998). This premise was based on the acquisition of a broad unresolved MALDI-TOF mass spectrum of pituitary LH $\beta$ cf with an average mass of $\sim 10000 \mathrm{Da}$ that, when the mass of the protein had been subtracted, gave the impression that a single intact $\mathcal{N}$-linked carbohydrate moiety had been retained. We have found that the unresolved, broad nature of MALDI-TOF mass spectra of glycoproteins is an indication of a population of molecules possessing wide microheterogeneity in terms of its carbohydrate content. This becomes apparent when the carbohydrates are investigated following the sequential use of glycanases or when the protein is broken down, as here with DTT, to its constituent peptides to improve spectral resolution.

The use of DTT to obtain a MALDI-TOF MS spectrum of reduced hCG $\beta$ cf produced a mass spectrum which enabled us to readily identify many of the $\mathcal{N}$-linked carbohydrates arising from the glycosylation moieties present on the metabolite (Jacoby et al. 2000). Of nine glycosylated peptides 

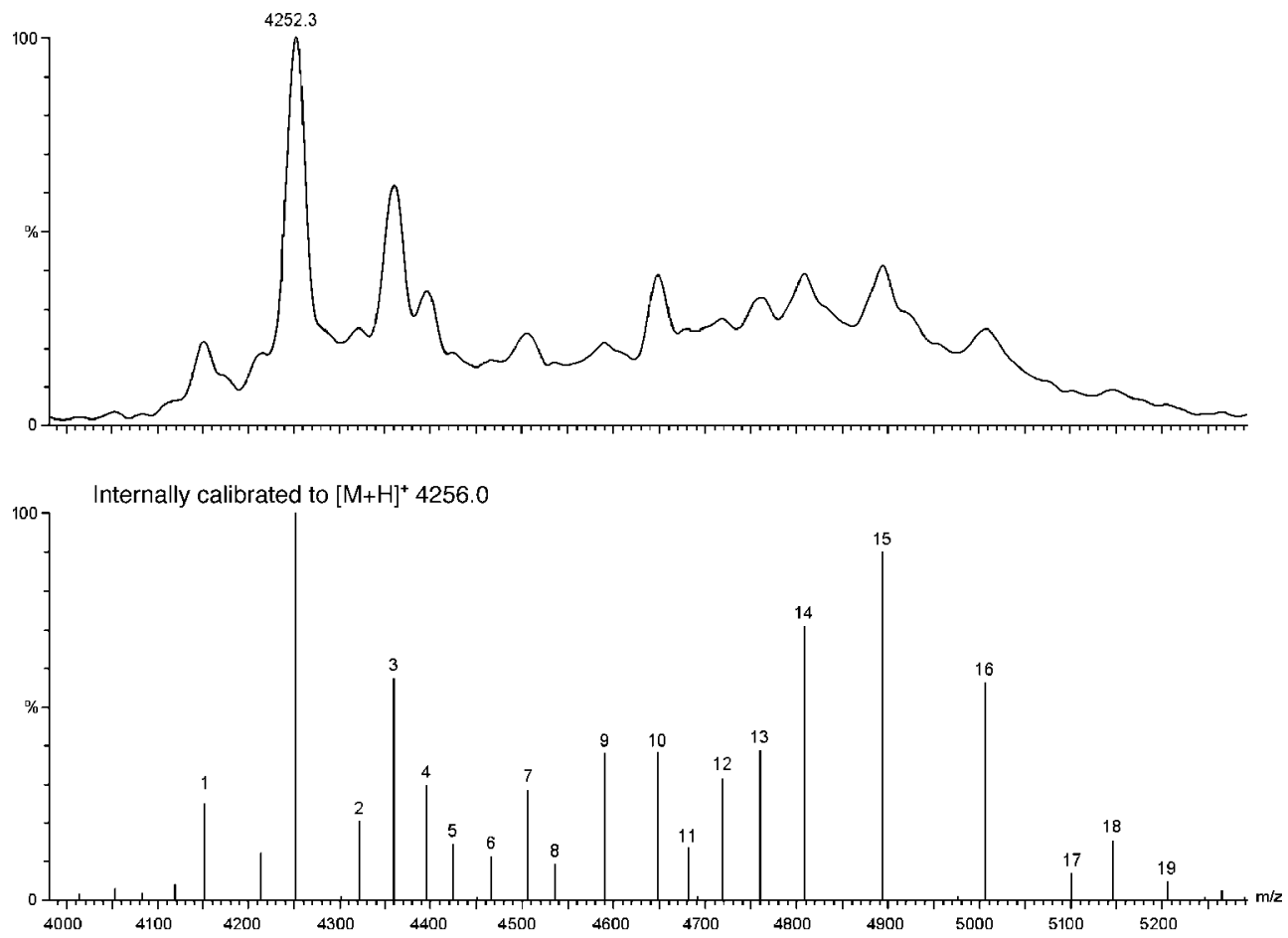

Figure 5 MALDI-TOF mass spectrum of DTT-reduced LH $\beta c f$ showing peaks in the $\mathrm{m} / \mathrm{z}$ range 4000-5300 (top) and the equivalent averaged centroids of those peaks (bottom) to facilitate peptide and carbohydrate identification.

detected we calculated that seven possessed two carbohydrate moieties, one a single carbohydrate moiety and the last either one or two carbohydrate moieties. It was expected that, as the primary sequence of the LH $\beta$-subunit possesses only a single consensus sequence permitting $\mathcal{N}$-linked glycosylation, an analogous but simple fingerprint spectrum of LH $\beta$ cf would be acquired using the same technique. By contrast with hCG $\beta c f$, we identified eighteen glycosylated peptides in the pituitary $\mathrm{LH} \beta \mathrm{cf}$ sample of which seven were determined to possess single carbohydrate moieties, six with two carbohydrate moieties and five with either one or two carbohydrate moieties.

Amino acid sequence analysis of $\mathrm{LH} \beta \mathrm{cf}$ isolated from pituitary tissue revealed the presence of two amino-terminal sequences in equal amounts starting at residues $\beta 6$ and $\beta 55$ (Birken et al. 1993). The primary structure of the glycosylated peptide has been determined to be $\beta 6-40$ by MALDI-TOF MS following $\mathcal{N}$-glycanase digestion (O'Connor et al. 1998, Birken et al. 2001). Subsequent analysis suggested that $\mathrm{LH} \beta \mathrm{cf}$ is more heterogeneous in the length of its constituent peptides than hCG $\beta c f$.
MALDI-TOF MS of reduced and carboxymethylated or alkylated LH $\beta$ cf revealed the presence of two non-glycosylated peptides spanning not only amino acids $\beta 55-93$ but also $\beta 49-93$ (Birken et al. 2001). Following DTT reduction, our MALDI-TOF MS data revealed the presence of only a single non-glycosylated peptide, $\beta 55-93$, in our sample of pooled LH $\beta$ cf. A peak corresponding to the peptide $\beta 49-93$, with a predicted mass of $4900 \cdot 8$, was not demonstrated in this study. However, following the same purification procedure (Birken et al. 1993), different batches of $\mathrm{LH} \beta \mathrm{cf}$ have shown variability in the proportional content of non-glycan peptides although both $\beta 55-93$ and $\beta 49-93$ peptides have usually been detected (S Birken, personal communication). It is possible that the signal from this peptide may not have been recognised by our MALDI detector, which may have been 'swamped' by greater concentrations of smaller peptides. A simpler explanation would be that the $\beta 49-93$ was not present in the batch of LH $\beta$ cf examined here.

In our previous analysis of hCG $\beta c f$ glycosylation, the prior reduction of the metabolite with DTT 
Table 4 Proposed structures of the oligosaccharides in the glycoforms contributing to the microheterogeneity of LH $\beta$ cf an Ile15 $\rightarrow$ Thr substitution (peaks 3, 8, 9, 12, 15, 16, 17 and 18). Where the masses found give rise to a variety of carbohydrate combinations on any one peptide, these are shown

\section{Proposed structure}

\section{Peak}

8

9

12

15

16

17

$$
\begin{aligned}
& \mathrm{GlcNAc} \beta 1 \rightarrow 4 \mathrm{GlcNAC}-\mathrm{Asn}+\mathrm{GlcNAc} \beta 1 \rightarrow 2 \operatorname{Man} \alpha 1 \rightarrow{ }_{3}^{6} \operatorname{Man} \beta 1 \rightarrow 4 \mathrm{GlcNAc} \beta 1 \rightarrow 4 \text { GlcNAc-Asn } \\
& \mathrm{Man} \beta 1 \rightarrow 4 \mathrm{GICNAc} \beta 1 \rightarrow 4 \mathrm{GlcNAC}-\mathrm{Asn}+\mathrm{GlcNAc} \beta 1 \rightarrow 4 \mathrm{Man} \beta 1 \rightarrow 4 \mathrm{GlcNAC} \beta 1 \rightarrow 4 \mathrm{GlcNAC}-\mathrm{Asn} \\
& \text { Man } \alpha 1>_{6} \text { or } 3 \\
& \text { GlcNAc } \beta 1 \rightarrow 4 \text { GICNAC-Asn }+ \text { GlcNAc } \beta 1 \rightarrow 4 \text { Man } \beta 1 \rightarrow 4 \text { GlcNAc } \beta 1 \rightarrow 4 \text { GlcNAc-Asn }
\end{aligned}
$$

18

$$
\text { GlcNAC-Asn }+ \text { GlcNAcB1 } \rightarrow \text { 4GlcNAc-Asn }
$$$$
\text { Inferred sugar }
$$$$
\text { mass }(m / z)
$$

$1340 \cdot 2$

$1388 \cdot 3$ 
Table 5 Proposed structures of the oligosaccharides in the glycoforms contributing to the microheterogeneity of LH $\beta$ cf containing both Trp $8 \rightarrow$ Arg and Ile15 $\rightarrow$ Thr substitutions (peaks $5,6,11,13$ and 14). Where the masses found give rise to a variety of carbohydrate combinations on any one peptide, these are shown

\section{Proposed structure}

Peak

5

6

11

13

14

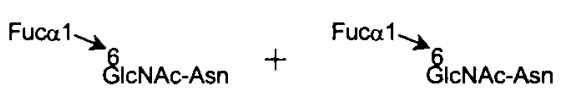

$\operatorname{Man\alpha } 1 \rightarrow{ }_{3}^{6} \operatorname{Man} \beta 1 \rightarrow 4$ GICNACB1 $\rightarrow 4$ GICNAC-Asn
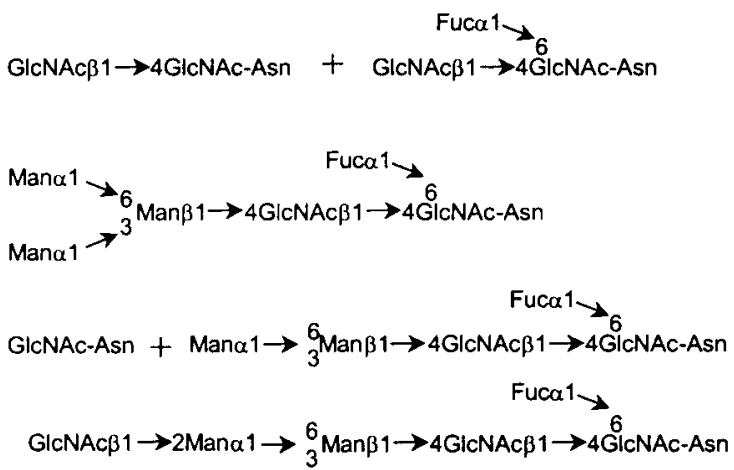

$\operatorname{Man} \alpha 1$

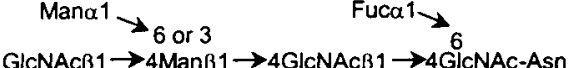

Inferred sugar

mass $(\mathrm{m} / \mathrm{z})$

$698 \cdot 7$

$730 \cdot 7$

958.9

$1038 \cdot 9$

$1080 \cdot 0$ enhanced the resolution of each glycated peptide to the extent that all peaks were well separated (Jacoby et al. 2000). When LH $\beta$ cf was reduced with DTT many more peaks corresponding to glycosylated peptides were seen in comparison with hCG $\beta$ cf and these were not as well resolved. The more complicated spectrum of DTT-reduced LH $\beta c f$, we realised, could not solely be accounted for by the hormone's increased glyco-microheterogeneity. However, the complex fingerprint could be accounted for by the presence of a second $\mathcal{N}$-linked glycosylation moiety. More importantly, a specific DNA polymorphism, which has previously been described, gives rise to a glycosylation signal sequence that may lead to the insertion of a second $\mathcal{N}$-linked glycosylation moiety (Furui et al. 1994, Pettersson et al. 1994, Suganuma et al. 1996, Nilsson et al. 1998). The commonly occurring vLH molecule possesses amino acid substitutions at $\beta 8$ and $\beta 15$. The substitution at $\beta 15$ of an isoleucine residue by a threonine residue results in the formation of a glycosylation consensus sequence theoretically permitting the addition of an additional $\mathcal{N}$-linked carbohydrate to the asparagine residue at $\beta 13$. In contrast to the studies of $h C G$, there has been little investigation of LH oligosaccharide composition. The asparagine-linked oligosaccharides on intact human LH have previously been elucidated by Green \& Baenziger $(1988 a, b)$ using conventional methodologies including radiolabelling reducible groups with $\mathrm{NaB}\left[{ }^{3} \mathrm{H}\right]_{4}$, release of oligosaccharides by $\mathcal{N}$-glycanase digestion, sequential digestions with endo- and exoglycosidase enzymes followed by HPLC and ionexchange separations. In a second study by Weisshaar et al. (1991), the dissociation of the dimeric hormone was followed by the release of oligosaccharides by hydrazinolysis from LH $\beta$ and from tryptic glycopeptides of LH $\alpha$. The subsequent characterisation of the $\mathcal{N}$-linked sugars largely by one and two dimensional protein nuclear magnetic resonance spectroscopy ( ${ }^{1} \mathrm{H}-\mathrm{NMR}$ ) permitted the attribution of the oligosaccharides to individual attachment sites. These studies, carried out before the genetic variants were known, found no evidence of an extra glycosylation site. Our data, by 
contrast, while finding evidence of fragments of many of the sugars described by Green \& Baenziger (1988a,b) and Weisshaar et al. (1991), could not have been analysed without the assumption that a second carbohydrate moiety was present on the molecule. We found that virtually all the glycosylation on peptides bearing a mutation at $\beta 15$ arises from either two separate sugars or from a strong possibility of there being two sugars on that peptide. It should be pointed out that due to the small quantity of pure sample available for this investigation it was not possible to obtain MS/ MS or MALDI-TOF evidence of peptide mass following exo- or endoglycosidase digestion that would confirm the presence of one or two mutations. Furthermore, in the earlier studies the separation techniques used largely confined the detection of LH $\mathcal{N}$-linked oligosaccharides to charged species possessing at least one terminating sialyl or sulfate group (Green \& Baenziger 1988a,b, Weisshaar et al. 1991). The fact that only degraded neutral species lacking terminating sialyl or sulfate groups were found here is therefore of interest even though MS has a bias towards the detection of neutral species. It may be that the MALDI-TOF used here detected only glycopeptides containing inefficiently compiled oligosaccharides or sugars degraded within the pituitary. However, as the lack of glycosidase activity within the pituitary is thought to leave LH carbohydrate moieties intact (Birken et al. 1996), it is more likely that degradation of the sugars occurred during an isolation or purification process or as a result of prompt fragmentation within the MALDI-TOF source.

The utilisation of the mass of the primary sequence of the $\mathrm{LH} \beta \mathrm{cf}$ glycosylated peptide with no substitutions, with a substitution at either $\beta 8$ or $\beta 15$ or at both positions to determine each peak's glycosylation profile, showed that all those species were present in our $\mathrm{LH} \beta \mathrm{cf}$ pooled sample. It has been suggested from molecular biology studies that the two point mutations occur together in the vLH molecule (Nilsson et al. 1997). The sites of the mutations within the $\mathrm{LH} \beta$ gene occur within close proximity of each other and may not necessarily be expected to separate as a result of crossover events during meiosis. However, most of the population studies have been based on differences in immunoassay reactivity measurements of $\mathrm{LH}$ rather than detection of the point mutations within the gene by molecular biology techniques (Haavisto et al. 1995, Nilsson et al. 1997, 1998). Thus it is possible that the two mutations can occur separately. Because of the mass differences conferred by these amino acid substitutions our results suggest that this is the case. This would have to be confirmed using molecular biology techniques but is strongly indicated by the data analysis presented here.

Clinically, abnormal LH secretion has been associated with a range of menstrual and fertility disorders such as polycystic ovary syndrome (PCOS) (Homburg et al. 1988, Regan et al. 1990, Balen et al. 1993, Risma et al. 1995). However, investigation into the function of $\mathrm{vLH}$ in PCOS and other fertility disorders have produced conflicting results (Rajkhowa et al. 1995, Suganuma et al. 1995, Takahasi et al. 1998, Tapanainen et al. 1999). MALDI-TOF MS of LH $\beta$ cf produces a complex but distinctive fingerprint spectrum. Analysis of the oligosaccharides remaining on $\mathrm{LH} \beta \mathrm{cf}$ will determine the $\mathcal{N}$-linked sugars remaining on the metabolite and also determine which sugars are present on LH $\beta$ peptides encoded by LH $\beta$ gene variants. By doing so it may, at a later date, be possible to show that this technique has a diagnostic value by linking the genetic polymorphism of the LH $\beta$ gene with the fertility disorders to which vLH has been associated. Ideally, sampling should be non-invasive and could take place from the urine. In individuals, the major breakdown product of $\mathrm{LH}$ in the urine is the core fragment LH $\beta$ cf. Direct MALDI-TOF MS analysis in our laboratories of unextracted non-pregnant female urine samples taken shortly after the LH surge demonstrates a spectral peak corresponding to LH $\beta c f$. This indicates that its concentration in urine is at a suitable level for detection purposes. Currently, ultrafiltration techniques are being investigated which will allow sample concentration and desalting as well as the removal of low molecular weight peptides that interfere with the MALDI-TOF mass spectrum following DTT reduction. By doing so, this clinical utility will potentially allow the facile identification of $\mathrm{LH}$ polymorphic variation in individuals prior to diagnosis by more complicated genetic tests which will be carried out as fresh stocks of the LH $\beta$ cf become available following in-house purification. 


\section{Acknowledgements}

This ongoing project is funded by the Joint Research Board of St Bartholomew's Hospital, London. We thank Dr Steven Birken for his critical comments and for supplying purified pituitary LH $\beta$ cf.

\section{References}

Balen AH, Tan SL \& Jacobs HS 1993 Hypersecretion of luteinizing hormone: a significant cause of infertility and miscarriage. British fournal of Obstetrics and Gynaecology 100 1082-1089.

Birken S, Armstrong EG, Kolks MAG, Cole LA, Agosto GM, Krichevsky A, Vaitukaitis JL \& Canfield RE 1988 Structure of the human chorionic gonadotropin beta-subunit fragment from pregnancy urine. Endocrinology 123 572-583.

Birken S, Chen Y, Gawiniwicz MA, Agosto GM, Canfield RE \& Hartree AS 1993 Structure and significance of human luteinizing hormone- $\beta$ core fragment purified from human pituitary extracts. Endocrinology 133 985-989.

Birken S, Kovalevskaya G \& O'Connor J 1996 Metabolism of hCG and hLH to multiple urinary forms. Molecular and Cellular Endocrinology 125 121-131.

Birken S, Gawinowicz MA, Maydelman Y \& Milgrom Y 2001 Metabolism of gonadotropins: comparisons of the primary structures of the human pituitary and urinary LH $\beta$ cores and the chimpanzee CG $\beta$ core demonstrate universality of core production. Foumal of Endocrinology 171 131-141.

Carlsen RB, Bahl OP \& Swaminathan N 1973 Human chorionic gonadotropin: linear amino acid sequence of the $\beta$ subunit. Fournal of Biological Chemistry 248 6810-6827.

Cole LA, Omrani A, Cermik D, Bahado-Singh RO \& Mahoney MJ 1998 Hyperglycosylated hCG, a potential alternative to hCG in Down syndrome screening. Prenatal Diagnosis 18 926-933.

Cole LA, Shahabi S, Oz UA, Rinne KM, Omrani A, Bahado-Singh RO \& Mahoney MJ 1999 Urinary screening tests for fetal Down syndrome: II. Hyperglycosylated hCG. Prenatal Diagnosis 19 351-359.

Elliott MM, Kardana A, Lustbader JW \& Cole LA 1997 Carbohydrate and peptide structure of the $\alpha$ - and $\beta$-subunits of human chorionic gonadotropin from normal and aberrant pregnancy and choriocarcinoma. Endocrine 7 15-32.

Furui K, Suganuma N, Tsukahara SI, Asada Y, Kikkawa F, Tanaka M, Ozawa T \& Tomoda Y 1994 Identification of two point mutations in the gene coding luteinizing hormone (LH) $\beta$-subunit, associated with immunologically anomalous LH variants. Fournal of Clinical Endocrinology and Metabolism 78 107-113.

Green ED \& Baenziger JU 1988 a Asparagine-linked oligosaccharides on lutotropin, follitropin, and thyrotropin (I). Fournal of Biological Chemistry 263 25-35.

Green ED \& Baenziger JU 1988 b Asparagine-linked oligosaccharides on lutotropin, follitropin, and thyrotropin (II). Fournal of Biological Chemistry 263 36-44.

Haavisto A-M, Pettersson K, Bergendahl M, Virkamäki A \& Huhtaniemi I 1995 Occurrence and biological properties of a common genetic variant of luteinizing hormone. Fournal of Clinical Endocrinology and Metabolism 80 1257-1263.

Homburg R, Armar NA, Eshel A, Adams J \& Jacobs HS 1988 Influence of serum luteinizing hormone concentrations on ovulation, conception, and early pregnancy loss in polycystic ovary syndrome. British Medical fournal 297 1024-1026.
Huhtaniemi I, Jiang M, Nilsson C \& Pettersson K 1999 Mutations and polymorphisms in gonadotropin genes. Molecular and Cellular Endocrinology 151 89-94.

Iles RK, Lee CL, Howes I, Davies S \& Edwards R 1992 Immunoreactive $\beta$-core-like material in postmenopausal urine: human chorionic gonadotrophin or LH origin? Evidence for the existence of LH core. Fournal of Endocrinology 133 459-466.

Iles RK, Javid MK, Gunn LK \& Chard T 1999 Cross-reaction with luteinizing hormone beta-core is responsible for the age-dependent increase of immunoreactive beta-core fragment of human chorionic gonadotropin in women with nonmalignant conditions. Clinical Chemistry 45 532-538.

Jacoby ES, Kicman AT, Laidler P \& Iles RK 2000 Determination of the glycoforms of human chorionic gonadotropin $\beta$-core fragment by matrix-assisted laser desorption/ionization time-of-flight mass spectrometry. Clinical Chemistry 46 1796-1803.

Kornfeld R \& Kornfeld S 1985 Assembly of asparagine-linked oligosaccharides. Annual Review of Biochemistry 54 631-664.

Kussmann M, Nordhoff E, Rahbek-Nielsen H, Haebel S, Rossel-Larsen M, Jakobsen L, Gobom J, Mirgorodskaya E, Kroll-Kristensen A, Palm L \& Roepstorff P 1997 Matrix-assisted laser desorption/ionization mass spectrometry sample preparation techniques designed for various peptide and protein analytes. Journal of Mass Spectrometry 32 593-601.

Lapthorn AJ, Harris DC, Littlejohn A, Lustbader JW, Canfield RE, Machin KJ, Morgan FJ \& Isaacs NW 1994 Crystal structure of human chorionic gonadotropin. Nature 369 455-461.

Markkanen SO, Töllikkö K, Vanha-Perttula T \& Rajaniemi H 1979 Disappearance of $\left[{ }^{125} \Pi\right.$ iodochorionic gonadotropin from the circulation in the rat: tissue uptake and degradation. Endocrinology 104 1540-1547.

Neven P, Iles RK, Howes I, Sharma K, Shepherd JH, Edwards R, Collins WP \& Chard T 1993 Substantial urinary concentrations of material resembling beta core fragment of chorionic gonadotrophin beta subunit in mid-menstrual cycle. Clinical Chemistry 39 1857-1860.

Nilsson C, Pettersson K, Millar RP, Coerver KA, Matzuk MM \& Huhtaniemi IT 1997 Worldwide frequency of a common genetic variant of luteinizing hormone: an international collaborative research. Fertility and Sterility 67 998-1004.

Nilsson C, Jiang M, Pettersson K, Iitiä A, Mäkelä M, Simonsen H, Easteal S, Herrara RJ \& Huhtaniemi I 1998 Determination of a common genetic variant of luteinizing hormone using DNA hybridisation and immunoassays. Clinical Endocrinology 49 369-376.

O'Connor JF, Kovalevskaya G, Birken S, Schlatterer JP, Schechter D, McMahon DJ \& Canfield RE 1998 The expression of the urinary forms of human luteinizing hormone beta fragment in various populations as assessed by a specific immunoradiometric assay. Human Reproduction 13 826-835.

Pettersson K, Ding YQ \& Huhtaniemi I 1991 Monoclonal antibodybased discrepancies between two-site immunometric tests for lutropin. Clinical Chemistry 37 333-340.

Pettersson K, Dahlén P, Lamminen T, Huoponen K \& Huhtaniemi I 1994 Gene polymorphism found in the LH beta gene of an immunologically anomalous variant of human luteinizing hormone. European Fournal of Endocrinology 130 (Suppl 2) 65

Pierce JG \& Parsons TF 1981 Glycoprotein hormones: structure and function. Annual Review of Biochemistry 50 465-495.

Rajkhowa M, Talbot JA, Jones PA, Petterson K, Haavisto AM, Huhtaniemi I \& Clayton RN 1995 Prevalence of an immunological LH $\beta$-subunit variant in a UK population of healthy women and women with polycystic ovary syndrome. Clinical Endocrinology 43 297-303.

Regan L, Owen EJ \& Jacobs HS 1990 Hypersecretion of luteinizing hormone, infertility and miscarriage. Lancet 336 1141-1144.

Risma KA, Clay CM, Nett TM, Wagner T, Yun J \& Nilson JH 1995 Targeted overexpression of luteinizing hormone in 
transgenic mice leads to infertility, polycystic ovaries, and ovarian tumours. PNAS 92 1322-1326.

Ryan RJ, Keutmann HT, Charlesworth MC, McCormick DJ, Millus RP, Calvo FR \& Vutyavanich T 1987 Structure-function relationships of gonadotrophins. Recent Progress in Hormone Research 43 383-429.

Shome B \& Parlow AF 1973 The primary structure of the hormonespecific beta subunit of human pituitary luteinizing hormone (hLH). Fournal of Clinical Endocrinology and Metabolism 36 618-621.

Suganuma N, Furui K, Furuhashi M, Asada Y, Kikkawa F \& Tomoda Y 1995 Screening of the mutations in luteinizing hormone $\beta$-subunit in patients with menstrual disorders. Fertility and Sterility 63 989-995.

Suganuma M, Furui K, Kikkawa F, Tomoda Y \& Furuhashi M 1996 Effects of mutations (Trp $8 \rightarrow$ Arg and Ile $15 \rightarrow$ Thr) in human luteinizing hormone $(\mathrm{LH}) \beta$-subunit on LH bioactivity in vitro and in vivo. Endocrinology 137 831-838.

Takahasi K, Kurioka H, Ozaki T, Kanasaki H, Kohsaka M, Miyazaki K \& Karino K 1998 Increased prevalence of luteinizing hormone beta-subunit variant in Japanese infertility patients. Human Reproduction 13 3338-3344.

Tapanainen JS, Koivunen R, Fauser BC, Taylor AE, Clayton RN, Rajkowa M, White D, Franks S, Anttila L, Pettersson KSI \& Huhtaniemi IT 1999 A new contributing factor to polycystic ovary syndrome: the genetic variant of luteinizing hormone. Fournal of Clinical Endocrinology and Metabolism 84 1711-1715.

Weisshaar G, Hiyama J, Renwick AGC \& Nimtz M 1991 NMR investigations of the $\mathcal{N}$-linked oligosaccharides at individual glycosylation sites of human lutropin. European Fournal of Biochemistry 195 257-268.

Wu H, Lustbader JW, Liu Y, Canfield RE \& Hendrickson WA 1994 Structure of human chorionic gonadotropin at $2 \cdot 6 \AA$ resolution from MAD analysis of the selenomethionyl protein. Structure $\mathbf{2}$ $545-558$.

Received in final form 14 November 2002 Accepted 25 November 2002 